\title{
Epidemiology and characteristics of febrile neutropenia in oncology patients from Spanish tertiary care hospitals: PINNACLE study
}

\author{
JAVIER DE CASTRO CARPEÑO ${ }^{1}$, PERE GASCÓN-VILAPLANA ${ }^{2}$, \\ ANA MARIA CASAS-FERNÁNDEZ-DE TEJERINA ${ }^{3}$, ANTONIO ANTÓN-TORRES ${ }^{4}$, RAFAEL LÓPEZ-LÓPEZ ${ }^{5}$, \\ AGUSTÍ BARNADAS-MOLINS ${ }^{6,7}$, JUAN JESÚS CRUZ-HERNÁNDEZ ${ }^{8}$, BARTOMEU MASSUTI-SUREDA ${ }^{9}$, \\ CARLOS CAMPS-HERRERO $^{10}$, ENRIQUE ARANDA-AGUILAR ${ }^{11}$ and FRANCISCO JOSÉ REBOLLO LASERNA ${ }^{12}$
}

\author{
${ }^{1}$ University Hospital La Paz, 28046 Madrid; ${ }^{2}$ Hospital Clinic of Barcelona, 08036 Barcelona; \\ ${ }^{3}$ University Hospital Virgen del Rocío, 41013 Seville; ${ }^{4}$ University Hospital Miguel Servet, 50009 Zaragoza; \\ ${ }^{5}$ University Hospital Complex of Santiago, 15706 Santiago de Compostela; ${ }^{6}$ Department of Medical Oncology, \\ Hospital of Saint Paul, 08025 Barcelona; ${ }^{7}$ Department of Medicine, Autonomous University of Barcelona, 08913 Barcelona; \\ ${ }^{8}$ University Hospital of Salamanca, 37007 Salamanca; ${ }^{9}$ University General Hospital of Alicante, 03010 Alicante; \\ ${ }^{10}$ University General Hospital of Valencia, University of Valencia, 46014 Valencia; ${ }^{11}$ Maimónides Institute of \\ Biomedical Research, Hospital Reina Sofía, University of Córdoba, 14004 Cordoba; \\ ${ }^{12}$ Sandoz Farmacéutica SA, 28023 Madrid, Spain
}

Received December 16, 2014; Accepted February 19, 2015

DOI: $10.3892 / \mathrm{mco} .2015 .524$

\begin{abstract}
Febrile neutropenia (FN) is one of the most common adverse events associated with myelosuppressive chemotherapy for cancer treatment. The objective of this study was to describe the incidence of hospitalization due to FN in Spanish tertiary care hospitals (PINNACLE study). This epidemiological, retrospective, multicenter, nationwide study involved 119 patients from oncology units of 10 Spanish tertiary care hospitals who were admitted for FN. The primary endpoint was to assess the epidemiology and characteristics of FN. The incidence of admissions due to FN in oncology patients was $2.0 \%$ (interquartile range [IQR], 1.6-3.0). In terms of fever and absolute neutrophil count (ANC), 37.0\% of the patients had a temperature of $\geq 38.2^{\circ} \mathrm{C}$ and an ANC of $\leq 500 / \mathrm{m}^{3}$. The number of patients who received prophylactic treatment with granulocyte colony-stimulating factor (G-CSF) was significantly higher in the palliative group $(32.6 \%)$ compared with that in the non-palliative group (13.5\%). The hospital length of stay was significantly shorter in patients who received prophylactic G-CSF compared with those who did not (5.0 days; IQR, 4.0-9.0 vs. 7.0 days; IQR, 5.0-11.0, respectively). The hospital length of stay was also significantly shorter in patients receiving palliative treatment (5.0 days;
\end{abstract}

Correspondence to: Dr Francisco José Rebollo Laserna, Sandoz Farmaceutica SA, 4 Avenida de la Osa Mayor, 28023 Madrid, Spain E-mail: francisco.rebollo@sandoz.com

Key words: febrile neutropenia, hospitalization, cancer, chemotherapy, Spain, PINNACLE study
IQR, 3.0-7.0) compared with those receiving non-palliative therapy (7.0 days; IQR, 5.0-12.0). In conclusion, the incidence of admissions due to $\mathrm{FN}$ in oncology patients was $2.0 \%$ and the duration of hospital stay was 7.0 days. Prophylactic G-CSF treatment was found to be associated with better outcomes and shorter hospital stays. Therefore, the use of this treatment becomes relevant for achieving better clinical outcomes and reducing hospitalization cost in the management of FN.

\section{Introduction}

Febrile neutropenia (FN) is one of the most common adverse events associated with the administration of myelosuppressive chemotherapy for cancer treatment (1). There are several definitions of FN; according to the European Society for Medical Oncology (ESMO), FN is defined as: 'An oral temperature of $>38.5^{\circ} \mathrm{C}$ or two consecutive readings of $>38.0^{\circ} \mathrm{C}$ for $2 \mathrm{~h}$ and an absolute neutrophil count (ANC) of $<0.5 \times 10^{9} / 1$, or expected to fall $<0.5 \times 10^{9} / l^{\prime}$ (2). An adverse effect of myelosuppressive treatment is the reduction of the ANC and a predisposition to infection from bacteria and fungi (3). The incidence of FN varies between 10 and $50 \%$ in solid tumors and is reportedly $\geq 80 \%$ in hematological malignancies (4). The mortality and comorbidities associated with $\mathrm{FN}$ require immediate hospitalization and treatment with antimicrobial agents $(5,6)$. The FN patient group is heterogeneous; therefore, the course of the infection and final outcome depend on individual patient factors such as age, tumor type and stage, previous hospitalizations, or severe comorbidities $(7,8)$.

Furthermore, FN frequently compromises the chemotherapeutic treatment by requiring a dose reduction and/or delay of treatment cycles, thereby directly affecting treatment efficacy, 
patient survival and quality of life (9). A retrospective analysis of breast cancer patients revealed that the survival rate was $40 \%$ in those receiving $\geq 85 \%$ of the chemotherapy dose, whereas the rate decreased to $21 \%$ in patients receiving $<85 \%$ of the dose (10). While dose reductions in palliative treatment may result in lower rates of tumor response, to the detriment of the patient's quality of life, dose reduction in curative or adjuvant therapies may be associated with an increased risk for disease recurrence and death (11-13). Prophylactic treatment with granulocyte colony-stimulating factor (G-CSF) was found to be beneficial regarding patient survival and a reduction in the risk of FN (14-16). Since it is common to develop FN during the first cycle of chemotherapy, European and US guidelines recommend the use of G-CSF in patients with an FN risk of $>20 \%$ (17-19).

Despite widespread research into chemotherapy usage, the risk of chemotherapy-induced $\mathrm{FN}$ in clinical practice is poorly documented. Moreover, only a limited number of studies have characterized FN hospitalization in oncology patients treated in Spanish clinics $(14,20)$. Therefore, the objective of the present study was to determine the incidence of admissions due to FN in Spanish tertiary care hospitals.

\section{Materials and methods}

Patient selection. This epidemiological, retrospective, multicenter, nationwide study assessed the demographic and clinical characteristics of 119 patients from oncology units of 10 Spanish tertiary care hospitals. The inclusion criteria were as folows: Patients diagnosed with cancer and receiving chemotherapy treatment; hospital admission due to $\mathrm{FN}$; complete clinical information available; and provision of signed informed consent. The criteria for excluding a patient were as follows: Participation in a clinical trial within the 3 months prior to hospitalization; and any concomitant disease liable to cause FN. All the procedures were performed in accordance with the guidelines established by the Declaration of Helsinki and the Ethics Committee of each hospital.

Variables and statistical analysis. The primary endpoint was to investigate the epidemiology and characteristics of FN in oncology patients receiving treatment in Spanish tertiary care hospitals (PINNACLE study). The incidence of admissions for FN was calculated as the ratio between the number of oncology patients admitted for FN and the total number of oncology patients receiving chemotherapy treatment in each hospital over a 3-month period (May-July, 2010). The secondary endpoints of the study included a description of the patients baseline clinical characteristics, the FN episode leading to hospitalization and its evolution, the different types of cancer and the antibiotic treatment for FN. Categorical variables were expressed as absolute and relative frequencies, and continuous variables as median and interquartile range (IQR). Categorical variables were compared using the $\chi^{2}$ or Fisher's exact test and continuous variables were compared using the Student's t-test or the Mann-Whitney U test (when non-parametric). Normal distribution was tested with the Shapiro-Wilk test. $\mathrm{P}<0.05$ was considered to indicate a statistically significant difference. All the statistical procedures were performed using SAS 9.2 software (SAS Institute Inc., Cary, NC, USA).
Table I. Demographic and clinical characteristics of patients prior to hospitalization.

\begin{tabular}{lc}
\hline Characteristics & $\begin{array}{c}\text { Patients } \\
(\mathrm{n}=119)\end{array}$ \\
\hline Age, years [median (IQR)] & $62.0(52.0-70.0)$ \\
Male gender, no. (\%) & $69(58.0)$ \\
Type of tumor, no. (\%) & \\
Lung & $34(28.6)$ \\
Breast & $26(21.9)$ \\
Colorectal & $14(11.8)$ \\
Sarcoma & $13(10.9)$ \\
Head and neck & $8(6.7)$ \\
Gynecological & $6(5.0)$ \\
Digestive & $5(4.2)$ \\
Bladder & $3(2.5)$ \\
Prostate & $3(2.5)$ \\
Other & $7(5.9)$ \\
Chemotherapy treatment intent, no. $(\%)$ & \\
Palliative & $43(36.1)$ \\
Non-palliative (curative and adjuvant) & $74(62.2)$ \\
NA & $2(1.7)$ \\
Prophylactic treatment with G-CSF, no. $(\%)$ & $25(21.0)$ \\
\hline
\end{tabular}

${ }^{\mathrm{a}}$ Other than colorectal. IQR, interquartile range; NA, not available; G-CSF, granulocyte colony-stimulating factor.

\section{Results}

Patient characteristics prior to hospitalization. Of the 119 patients, $69(58.0 \%)$ were men and 50 (42.0\%) were women. The median age was 62.0 years (IQR, 52.0-70.0). The demographic and clinical characteristics of the patients prior to hospitalization are summarized in Table I. The most common types of cancer were lung (28.6\% of patients), breast $(21.9 \%)$, colorectal (11.8\%) and sarcoma (10.9\%). All the patients were receiving chemotherapy treatment. The intent of the treatment was palliative in $36.1 \%$ and non-palliative (curative and adjuvant) in $62.2 \%$ of the patients. Prior to hospitalization, $21.0 \%$ of the patients were under prophylactic treatment with G-CSF.

Characteristics associated with hospitalization due to FN in all patients. The epidemiological and clinical characteristics associated with FN hospitalization in all the patients are presented in Table II. The incidence of admissions due to FN in oncology patients over a 3-month period was $2.0 \%$ (IQR, 1.6-3.0). When classifying $\mathrm{FN}$ hospitalization by fever and $\mathrm{ANC}, 37.0 \%$ of the patients had a temperature of $\geq 38.2^{\circ} \mathrm{C}$ and $\mathrm{ANC} \leq 500 / \mathrm{m}^{3}$; $31.9 \%$ had a temperature of $<38.2^{\circ} \mathrm{C}$ and $\mathrm{ANC} \leq 500 / \mathrm{m}^{3}$; $14.3 \%$ had a temperature of $<38.2^{\circ} \mathrm{C}$ and $\mathrm{ANC}>500 / \mathrm{m}^{3}$; and $9.2 \%$ had a temperature of $\geq 38.2^{\circ} \mathrm{C}$ and $\mathrm{ANC}>500 / \mathrm{m}^{3}$. Overall, the median duration of the fever was 2.0 days (IQR, 1.0-3.0) and that of neutropenia 3.0 days (IQR, 2.0-4.5). The median duration of the hospital stay was 7.0 days (IQR, 5.0-11.0). The median duration of the hospital stay was significantly lower 
Table II. Epidemiological and clinical characteristics associated with hospitalization due to $\mathrm{FN}$ in all patients $(\mathrm{n}=119)$.

\begin{tabular}{|c|c|}
\hline Characteristics & Values \\
\hline $\begin{array}{l}\text { Incidence of admissions due to } \mathrm{FN}, \% \\
\text { [median (IQR)] }\end{array}$ & $2.0(1.6-3.0)$ \\
\hline \multicolumn{2}{|l|}{$\begin{array}{l}\text { Episodes of fever and neutropenia } \\
\text { at the admission day, no. }(\%)\end{array}$} \\
\hline Temperature $\geq 38.2^{\circ} \mathrm{C}, \mathrm{ANC} \leq 500 / \mathrm{m}^{3}$ & $44(37.0)$ \\
\hline Temperature $<38.2^{\circ} \mathrm{C}, \mathrm{ANC} \leq 500 / \mathrm{m}^{3}$ & $38(31.9)$ \\
\hline Temperature $<38.2^{\circ} \mathrm{C}, \mathrm{ANC}>500 / \mathrm{m}^{3}$ & $17(14.3)$ \\
\hline Temperature $\geq 38.2^{\circ} \mathrm{C}, \mathrm{ANC}>500 / \mathrm{m}^{3}$ & $11(9.2)$ \\
\hline NA & $9(7.6)$ \\
\hline Duration of fever, days [median (IQR)] & $2.0(1.0-3.0)$ \\
\hline $\begin{array}{l}\text { Duration of the neutropenia, days } \\
\text { [median (IQR)] }\end{array}$ & $3.0(2.0-4.5)$ \\
\hline \multicolumn{2}{|l|}{$\begin{array}{l}\text { Duration of hospital stay, days } \\
\text { [median (IQR)] }\end{array}$} \\
\hline All patients & $7.0(5.0-11.0)$ \\
\hline Patients previously treated with G-CSF & $5.0(4.0-9.0)$ \\
\hline \multicolumn{2}{|l|}{$\begin{array}{l}\text { Modifications in chemotherapy } \\
\text { treatment, no. }(\%)\end{array}$} \\
\hline Dose reduction & $13(11.1)$ \\
\hline Dose reduction and delay of cycles & $14(12.0)$ \\
\hline Delay of cycles & $40(34.2)$ \\
\hline Delay of cycles and discontinuation & $1(0.8)$ \\
\hline Discontinuation & $31(26.5)$ \\
\hline NA & $19(16.2)$ \\
\hline \multicolumn{2}{|l|}{ Antibiotic treatment for FN, no. (\%) } \\
\hline $\begin{array}{l}\text { Penicillin and cephalosporin (piperacillin- } \\
\text { tazobactam, amoxicillin-clavulanate, } \\
\text { cefepime, ceftazidime) }\end{array}$ & $82(68.9)$ \\
\hline Quinolones (ciprofloxacin, levofloxacin) & $61(51.3)$ \\
\hline $\begin{array}{l}\text { Carbapenems (meropenem, } \\
\text { imipenem, ertapenem) }\end{array}$ & $52(43.7)$ \\
\hline Aminoglycosides (amikacin) & $23(19.3)$ \\
\hline Vancomycin & $16(13.5)$ \\
\hline Other antibiotics & $14(11.8)$ \\
\hline $\begin{array}{l}\text { Antifungal agents (fluconazole, } \\
\text { metronidazole) }\end{array}$ & $9(7.6)$ \\
\hline Mortality during hospitalization, no. (\%) & $8(6.7)$ \\
\hline FN & $2(25.0)$ \\
\hline Disease progression & $5(62.5)$ \\
\hline Other & $1(12.5)$ \\
\hline
\end{tabular}

FN, febrile neutropenia; ANC, absolute neutrophil count; NA, not available; G-CSF, granulocyte colony-stimulating factor; IQR, interquartile range.

$(\mathrm{P}=0.05)$ in patients who had previously received prophylactic treatment with G-CSF (5.0 days, IQR, 4.0-9.0) compared with those who had not (7.0 days, IQR, 5.0-11.0). As a consequence of FN, chemotherapy treatment was modified in the following manner: Dose reduction ( $11.1 \%$ of the patients), dose reduction and delay of cycles (12.0\%), delay of cycles only (34.2\%),
Table III. Epidemiological and clinical characteristics associated with hospitalization due to $\mathrm{FN}$ in patients classified according to palliative or non-palliative intent of chemotherapy.

\begin{tabular}{|c|c|c|}
\hline Characteristics & $\begin{array}{c}\text { Palliative } \\
\text { chemotherapy } \\
(n=43)\end{array}$ & $\begin{array}{l}\text { Non-palliative } \\
\text { chemotherapy } \\
(n=74)\end{array}$ \\
\hline $\begin{array}{l}\text { Number of previous } \\
\text { chemotherapy cycles, } \\
\text { median (IQR) }\end{array}$ & $2.0(1.0-3.0)$ & $2.0(1.0-4.0)$ \\
\hline $\begin{array}{l}\text { Prophylactic treatment } \\
\text { with G-CSF, no. }(\%)\end{array}$ & $14(32.6)$ & $10(13.5)$ \\
\hline \multicolumn{3}{|l|}{$\begin{array}{l}\text { Episodes of FN on the } \\
\text { day of admission, no. (\%) }\end{array}$} \\
\hline $\begin{array}{l}\text { Temperature } \geq 38.2^{\circ} \mathrm{C} \\
\text { ANC } \leq 500 / \mathrm{m}^{3}\end{array}$ & $21(48.9)$ & $24(32.4)$ \\
\hline $\begin{array}{l}\text { Temperature }<38.2^{\circ} \mathrm{C}, \\
\text { ANC } \leq 500 / \mathrm{m}^{3}\end{array}$ & $13(30.2)$ & $28(37.8)$ \\
\hline $\begin{array}{l}\text { Temperature }<38.2^{\circ} \mathrm{C}, \\
\text { ANC }>500 / \mathrm{m}^{3}\end{array}$ & 5 (11.6) & $11(14.9)$ \\
\hline $\begin{array}{l}\text { Temperature } \geq 38.2^{\circ} \mathrm{C}, \\
\text { ANC }>500 / \mathrm{m}^{3}\end{array}$ & $4(9.3)$ & $7(9.5)$ \\
\hline NA & $0(0.0)$ & $4(5.4)$ \\
\hline $\begin{array}{l}\text { Duration of hospital stay, } \\
\text { days [median (IQR)] }\end{array}$ & $5.0(3.0-7.0)$ & $7.0(5.0-12.0)$ \\
\hline \multicolumn{3}{|l|}{$\begin{array}{l}\text { Modifications in } \\
\text { chemotherapy } \\
\text { treatment, no. }(\%)\end{array}$} \\
\hline Dose reduction & $6(14.0)$ & $7(9.5)$ \\
\hline $\begin{array}{l}\text { Dose reduction and } \\
\text { delay of cycles }\end{array}$ & $2(4.6)$ & $12(16.2)$ \\
\hline Delay of cycles & $16(37.2)$ & $24(32.4)$ \\
\hline Discontinuation $^{\mathrm{a}}$ & $11(25.6)$ & $20(27.0)$ \\
\hline NA & 8 (18.6) & $11(14.9)$ \\
\hline
\end{tabular}

ancluded only discontinuation and delay of cycles and discontinuation. FN, febrile neutropenia; IQR, interquartile range; G-CSF, granulocyte colony-stimulating factor; ANC, absolute neutrophil count; NA, not available.

delay of cycles and discontinuation $(0.8 \%)$ and discontinuation only $(26.5 \%)$. The antibiotic treatment for FN consisted of penicillin and cephalosporin (piperacillin-tazobactam, amoxicillin-clavulanate, cefepime or ceftazidime) in $68.9 \%$ of the patients, quinolones (ciprofloxacin or levofloxacin) in $51.3 \%$, carbapenems (meropenem, imipenem or ertapenem) in $43.7 \%$, aminoglycosides (amikacin) in $19.3 \%$, vancomycin in $13.5 \%$ and antifungal agents (fluconazole or metronidazole) in $7.6 \%$. The mortality rate during hospitalization was $6.7 \%$, of which $25 \%$ was due to FN (1.7\% of the total patients).

Characteristics associated with hospitalization due to FN in patients classified by intent of chemotherapy treatment. The epidemiological and clinical characteristics associated with FN hospitalization of patients receiving palliative or non-palliative chemotherapy are shown in Table III. The median number of previous chemotherapy cycles was 2.0 (IQR, 1.0-3.0) for the 
palliative group and 2.0 (IQR, 1.0-4.0) for the non-palliative group. The number of patients who received prophylactic treatment with G-CSF was significantly higher in the palliative group compared with that in the non-palliative group (32.6 vs. $13.5 \% ; \mathrm{P}=0.0139)$. There were no significant differences between the two groups regarding the duration of fever and neutropenia (data not shown), or the characteristics of the FN episode on the day of admission (temperature and ANC). The median duration of hospital stay was significantly shorter for the palliative compared with the non-palliative group (5.0 days; IQR, 3.0-7.0 vs. 7.0 days; IQR, 5.0-12.0; $\mathrm{P}=0.0025$ ). Delay of cycles was the most common modification of chemotherapy, occuring in 37.2 and $32.4 \%$ of patients in the palliative and non-palliative group, respectively. The modifications in chemotherapy did not differ significantly between the groups. All the patients who succumbed to the disease were receiving palliative treatment. The antibiotic treatment for FN was similar between the palliative and non-palliative groups.

\section{Discussion}

FN is a serious medical condition affecting patients receiving chemotherapy for cancer. The number of studies investigating FN in Spanish clinical practice is limited $(14,20)$. In 2013, the PRAXIS study prospectively evaluated FN episodes in 734 patients with breast cancer and 291 with lymphoma (20). By contrast, the present study focused on a wide spectrum of malignancies, such as sarcoma, lung, breast and colorectal cancer, allowing us to characterize FN in cancer with a wider perspective. The risk of developing FN is normally associated with the cancer treatment. For example, hematological malignancies are associated with a higher risk of FN compared with solid tumors, due to the process of the disease and its treatment $(21,22)$. When comparing solid tumors, patients with lung cancer appear to exhibit a higher incidence rate of FN (5). In our study of patients with almost exclusively solid tumors, the overall incidence of FN was 2.0\% (IQR, 1.6-3.0\%). This result is in accordance with the findings for patients with breast cancer from the PRAXIS study (2.0\%; IQR, 1.0-3.0\%) (20).

There are several definitions of FN. According to ESMO, FN is defined as 'an oral temperature of $>38.5^{\circ} \mathrm{C}$ or two consecutive readings of $>38.0^{\circ} \mathrm{C}$ for $2 \mathrm{~h}$ and an ANC of $<0.5 \times 10^{9} / 1$, or expected to fall $<0.5 \times 10^{9} / 1^{\prime}$ (2). According to the Infectious Diseases Society of America, FN is defined as 'single oral temperature of $\geq 38.0^{\circ} \mathrm{C}\left(101.4^{\circ} \mathrm{F}\right)$ for $\geq 1 \mathrm{~h}$ '. Neutropenia is defined as 'a neutrophil count of $<500$ cells $/ \mathrm{mm}^{3}$, or a count of $<1,000$ cells $/ \mathrm{mm}^{3}$ with a predicted decrease to $<500$ cells $/ \mathrm{mm}^{3}$ ' (6). In the PINNACLE study, 119 patients were hospitalized due to an episode of FN; however, only $37.0 \%$ of the patients actually met the criteria of temperature $\geq 38.2^{\circ} \mathrm{C}$ and $\mathrm{ANC} \leq 500 / \mathrm{m}^{3}$. Of note, $14.3 \%$ of the patients had a temperature of $<38.2^{\circ} \mathrm{C}$ and an ANC of $>500 / \mathrm{m}^{3}$. One explanation for the inclusion of these patients is that their clinical characteristics, disease evolution, or comorbidities required urgent hospitalization. It has also been suggested that, when the patient presented at the emergency room (ER), there were no experienced oncology specialists on duty who could properly identify and treat the chemotherapy-induced neutropenia. Thus, the lack of available specialists may have led to an increase in the number of admissions. In fact, it has been proposed that certain patients with a low risk of complications should be treated as outpatients $(23,24)$, particularly given the medical cost of patient hospitalization and its duration $(1,5,25)$.

The addition of G-CSF has been demonstrated to reduce the duration of neutropenia and, consequently, the duration of antibiotic treatment and hospital stay (14-16). In fact, the Spanish Society of Medical Oncology, in accordance with European and US guidelines, recommends G-CSF use in patients with a risk of FN of $>20 \%$ (17-19). A multicenter trial involving 210 patients from five Spanish hospitals revealed that the duration of hospitalization was significantly shorter in the group of patients receiving G-CSF (5 days), compared with that in the control group (7 days) (14). Similarly, in our study, prophylactic treatment with G-CSF resulted in significantly shorter duration of hospital stay (5.0 days; IQR, 4.0-9.0) compared with the overall population (7.0 days; IQR, 5.0-11.0). FN may compromise chemotherapeutic treatment by resulting in the need for dose reduction and/or delay of cycles, directly affecting the efficacy of the treatment, patient survival and quality of life $(9,10)$. Thus, prophylactic G-CSF is recommended for patients receiving curative or adjuvant therapies in order to maintain the complete chemotherapy dose (18). By contrast, a dose reduction may be less clinically significant in the palliative treatment setting (26). In our study, the incidence of dose reduction was higher in the palliative compared with that in the non-palliative group (14.0 vs. 9.5\%, respectively). However, it is of interest that the combination of dose reduction and delay was higher in the non-palliative group (4.7 vs. $16.2 \%$, respectively). Furthermore, more patients in the palliative group received prophylactic treatment with G-CSF (32.6 vs. $13.5 \%$, respectively). This finding may be attributed to the more favourable disease status of patients in the non-palliative group affecting decision making. In fact, all FN-related deaths during hospitalization were observed in the palliative treatment group. Several studies have quantified the overall in-hospital mortality rate for chemotherapy patients as being 7.1-9.5\%, with an FN-related mortality of $3.0-11.0 \%(5,21,27-29)$. The rates in the PINNACLE study were $6.7 \%$ for any cause and $1.7 \%$ due to $\mathrm{FN}$, which were marginally lower compared with those in the published literature.

The main limitation of the present study was the retrospective nature of the available data. The availability of more clinical information, such as prior chemotherapy regimens or hospitalization, cancer stage (advanced or uncontrolled), or concurrent treatment for FN with G-CSF (not only prophylactic), may have improved the content of the study. However, in our opinion, this study demonstrates the actual status of clinical practice within the oncology units of tertiary care hospitals in Spain. Another limitation of the study was the intrinsic heterogeneity between hospitals, which may have resulted in different responses. For example, certain hospitals with specialists on duty in the ER did not admit patients with neutropenia and absence of fever. By contrast, other hospitals, with no qualified specialists on duty, proceeded to admit such patients.

In conclusion, the incidence of admissions due to $\mathrm{FN}$ in oncology patients was found to be $2.0 \%$ and the median duration of hospital stay was 7.0 days. Almost two-thirds of patients hospitalized due to FN in Spanish tertiary care hospitals do 
not meet the established criteria of FN definition. Prophylactic treatment with G-CSF is associated with a better outcome and shorter hospital stay. Therefore, the adequate evaluation of patients and the use of prophylactic treatments become relevant for optimizing clinical outcomes and reducing hospitalization costs in the management of FN.

\section{Acknowledgements}

The authors would like to thank to Carme Font (MD, Hospital Clínic de Barcelona, Spain), Maria Teresa Cano Osuna and Pedro Sánchez Mauriño (both MDs, from the Hospital Universitario Reina Sofía, Córdoba, Spain). The authors would also like to thank Pablo Vivanco Jódar (PhD, Meisys) for assisting with the preparation of the manuscript. The PINNACLE study was sponsored by Sandoz Farmaceútica SA (Madrid, Spain). FJRL is an employee of Sandoz Farmaceutica SA.

\section{References}

1. Caggiano V, Weiss RV, Rickert TS and Linde-Zwirble WT: Incidence, cost and mortality of neutropenia hospitalization associated with chemotherapy. Cancer 103: 1916-1924, 2005.

2. de Naurois J, Novitzky-Basso I, Gill MJ, Marti FM, Cullen MH and Roila F; ESMO Guidelines Working Group: Management of febrile neutropenia: ESMO Clinical Practice Guidelines. Ann Oncol 21 (Suppl 5): v252-v256, 2010.

3. Silber JH, Fridman M, DiPaola RS, Erder MH, Pauly MV and Fox KR: First-cycle blood counts and subsequent neutropenia, dose reduction, or delay in early-stage breast cancer therapy. J Clin Oncol 16: 2392-2400, 1998.

4. Klastersky J: Management of fever in neutropenic patients with different risks of complications. Clin Infect Dis 39 (Suppl 1): S32-S37, 2004.

5. Kuderer NM, Dale DC, Crawford J, Cosler LE and Lyman GH: Mortality, morbidity and cost associated with febrile neutropenia in adult cancer patients. Cancer 106: 2258-2266, 2006.

6. Hughes WT, Armstrong D, Bodey GP, et al: 2002 guidelines for the use of antimicrobial agents in neutropenic patients with cancer. Clin Infect Dis 34: 730-751, 2002.

7. Talcott JA, Finberg R, Mayer RJ and Goldman L: The medical course of cancer patients with fever and neutropenia. Clinical identification of a low-risk subgroup at presentation. Arch Intern Med 148: 2561-2568, 1988.

8. Gala Peralta S, Cardesa Salzman T, García García JJ, Estella Aguado J, Gené Giralt A and Luaces Cubells C: Bacteraemia risk criteria in the paediatric febrile neutropenic cancer patient. Clin Transl Oncol 7: 165-168, 2005 (In Spanish).

9. Cairo MS: Dose reductions and delays: Limitations of myelosuppressive chemotherapy. Oncology (Williston Park) 14 (Suppl 8): 21-31, 2000.

10. Bonadonna G, Moliterni A, Zambetti M, Daidone MG, Pilotti S, Gianni L and Valagussa P: 30 years' follow up of randomised studies of adjuvant CMF in operable breast cancer: Cohort study. BMJ 330: 217-222, 2005.

11. Chang J: Chemotherapy dose reduction and delay in clinical practice. Evaluating the risk to patient outcome in adjuvant chemotherapy for breast cancer. Eur J Cancer 36 (Suppl 1): S11-S14, 2000

12. Lyman GH, Dale DC and Crawford J: Incidence and predictors of low dose-intensity in adjuvant breast cancer chemotherapy: a nationwide study of community practices. J Clin Oncol 21 4524-4531, 2003.
13. Lyman GH, Michels SL, Reynolds MW, Barron R, Tomic KS and Yu J: Risk of mortality in patients with cancer who experience febrile neutropenia. Cancer 116: 5555-5563, 2010.

14. García-Carbonero R, Mayordomo JI, Tornamira MV, et al: Granulocyte colony-stimulating factor in the treatment of high-risk febrile neutropenia: A multicenter randomized trial. J Natl Cancer Inst 93: 31-38, 2001.

15. Gómez Raposo C, Pinto Marín A and González Barón M: Colony-stimulating factors: Clinical evidence for treatment and prophylaxis of chemotherapy-induced febrile neutropenia. Clin Transl Oncol 8: 729-734, 2006

16. Kuderer NM, Dale DC, Crawford J and Lyman GH: Impact of primary prophylaxis with granulocyte colony-stimulating factor on febrile neutropenia and mortality in adult cancer patients receiving chemotherapy: A systematic review. J Clin Oncol 25: 3158-3167, 2007.

17. Smith TJ, Khatcheressian J, Lyman GH, et al: 2006 update of recommendations for the use of white blood cell growth factors: An evidence-based clinical practice guideline. J Clin Oncol 24: 3187-3205, 2006.

18. Aapro MS, Bohlius J, Cameron DA, et al; European Organisation for Research and Treatment of Cancer: 2010 update of EORTC guidelines for the use of granulocyte-colony stimulating factor to reduce the incidence of chemotherapy-induced febrile neutropenia in adult patients with lymphoproliferative disorders and solid tumours. Eur J Cancer 47: 8-32, 2011.

19. Carrato A, Paz-Ares Rodríguez L, Rodríguez Lescure A, et al; Spanish Society of Medical Oncology (SEOM): Spanish Society of Medical Oncology consensus for the use of haematopoietic colony-stimulating factors in cancer patients. Clin Transl Oncol 11: 446-454, 2009.

20. Jolis L, Carabantes F, Pernas S, Cantos B, López A, Torres P, Funes C, Caballero D, Benedit P and Salar A; PRAXIS Study Group: Incidence of chemotherapy-induced neutropenia and current practice of prophylaxis with granulocyte colony-stimulating factors in cancer patients in Spain: A prospective, observational study. Eur J Cancer Care (Engl) 22: 513-521, 2013.

21. Klastersky J, Paesmans M, Rubenstein EB, et al: The Multinational Association for Supportive Care in Cancer risk index: A multinational scoring system for identifying low-risk febrile neutropenic cancer patients. J Clin Oncol 18: 3038-3051, 2000.

22. Lyman GH, Lyman $\mathrm{CH}$ and Agboola O: Risk models for predicting chemotherapy-induced neutropenia. Oncologist 10: 427-437, 2005.

23. Innes $\mathrm{H}$ and Marshall E: Outpatient therapy for febrile neutropenia. Curr Opin Oncol 19: 294-298, 2007.

24. Flowers CR, Seidenfeld J, Bow EJ, et al: Antimicrobial prophylaxis and outpatient management of fever and neutropenia in adults treated for malignancy: American Society of Clinical Oncology clinical practice guideline. J Clin Oncol 31: 794-810, 2013.

25. Lathia N, Mittmann N, DeAngelis C, Knowles S, Cheung M, Piliotis E, Shear N and Walker S: Evaluation of direct medical costs of hospitalization for febrile neutropenia. Cancer 116: 742-748, 2010

26. Saloustros E, Tryfonidis K and Georgoulias V: Prophylactic and therapeutic strategies in chemotherapy-induced neutropenia. Expert Opin Pharmacother 12: 851-863, 2011.

27. Clark OA, Lyman GH, Castro AA, Clark LG and Djulbegovic B: Colony-stimulating factors for chemotherapy-induced febrile neutropenia: A meta-analysis of randomized controlled trials. J Clin Oncol 23: 4198-4214, 2005.

28. Wong GC and Tan BH: Use of antibiotics in a haematology ward - an audit. Ann Acad Med Singapore 37: 21-26, 2008.

29. Jin J, Lee YM, Ding Y, Koh LP, Lim SE, Lim R, Tambyah PA and Hsu LY: Prospective audit of febrile neutropenia management at a tertiary university hospital in Singapore. Ann Acad Med Singapore 39: 453-459, 2010. 